\title{
INTERPRETAÇÕES SOBRE O FUNCIONÁRIO GREVISTA NA MÍDIA LOCAL
}

\author{
Daviane Cristine Miranda Araujo (Colaboradora Externa) \\ Lidia Maria Gonçalves (Orientadora - UEL)
}

\section{RESUMO}

Este trabalho faz parte das análises realizadas durante a nossa participação no projeto de extensão universitária intitulado "Impulso no conhecimento da Língua Portuguesa por meio dos gêneros textuais da esfera jornalística em instituições de ensino da região de Londrina/PR". Buscamos analisar como a mídia local, por meio dos jornais Folha de Londrina (Portal Bonde) e Jornal de Londrina, elucidou a identidade dos funcionários públicos do Estado do Paraná no período de uma das greves. Selecionamos dois textos de cada uma das empresas jornalísticas para análise e apresentamos referencial teórico na Semântica Argumentativa, tendo, algumas vezes, o respaldo da Análise do Discurso de linha francesa e da Linguística Textual. A mídia procura aparentar imparcialidade, mas a escolha lexical utilizada deixa transparecer posicionamentos. Os jornais Folha de Londrina (Portal Bonde) e Jornal de Londrina mostraram-se favoráveis à greve do funcionalismo público estadual, mas, mesmo assim, percebemos que, muitas vezes, o professor foi silenciado, não teve oportunidade para se expressar e, quando o fez, foi por meio de outras instâncias, como a APP/Sindicato dos Trabalhadores em Educação Pública, ou por meio de professores universitários, não componente da educação básica.

\section{INTRODUÇÃO}

Neste trabalho, analisamos a produção jornalística local, veiculada no Jornal de Londrina (JL) e na Folha de Londrina (Portal Bonde), ambos em contexto online, eleito em decorrência do fácil acesso a estes textos e do seu amplo poder de penetração social. Nosso objetivo é analisar, sob a perspectiva da Semântica Argumentativa, matérias jornalísticas publicadas nos referidos jornais, no período de 10/02/2015 a 18/03/2015, época da primeira fase da recente greve do funcionalismo público estadual do Paraná. Portanto, nosso corpus constitui-se de textos publicados durante este período e que têm como foco o funcionário público, mais precisamente, a repercussão que a mídia local deu ao movimento grevista dos professores da rede pública do Estado do Paraná. Tais matérias jornalísticas repercutem uma imagem sobre os professores, categoria profissional a qual pertencemos, e estes textos têm ação de influência sobre a opinião pública acerca do movimento grevista e evocam marcas da identidade desta classe de trabalhadores. Interessa-nos analisar como essas invocações foram construídas no discurso midiático.

Optamos pela escolha do nosso tema de pesquisa tendo em vista o ocorrido no período de greve dos professores e demais funcionários do Estado do Paraná, cuja mobilização deu-se em busca do reconhecimento de seu trabalho por meio do reajuste salarial da data-base, previsto em $8,17 \%$, e para não utilização de fundos da Paraná Previdência para equilíbrio das despesas do Estado, dentre outras exigências. Tal apropriação de recursos foi considerada injusta pela categoria afetada, por ser um 


\section{SEMINÁRIO DE PESQUISA EM CIÊNCIAS HUMANAS - SEPECH \\ Humanidades, Estado e desafios didático-científicos \\ Londrina, 27 a 29 de julho de 2016}

dinheiro destinado à aposentadoria destes servidores. Este tema foi pauta relevante na mídia estadual, com repercussão nacional e internacional.

Recorremos à Semântica Argumentativa por tratarmos, exatamente, da interpretação dos argumentos proferidos pelos repórteres com relação aos direitos da categoria dos funcionários públicos. E, por meio de tal área do saber, investigamos o devido reconhecimento que as empresas jornalísticas de maior circulação local deram ao ocorrido e como a identidade dos educadores paranaenses foi veiculada por intermédio dessas duas empresas de mídia de considerável prestígio regional.

Quanto à argumentação, seus estudos iniciaram com a Retórica, uma ciência do discurso que surgiu durante o século V a.C., em Atenas. Deu-se então, o início dos estudos da linguagem.

Para Górgias - orador grego (487 a.C - 380 a.C), considerado o pai dos sofistas - a linguagem é dotada de força persuasiva com uso de recursos significativos, como antítese, ritmos, paralelismos, metáforas, entre outros. Com essa visão mais ampla (estética e literária) acerca da retórica, a arte de argumentar transformou-se num grande trunfo no desenvolvimento da criticidade do cidadão, essencialmente, nos campos da política e do direito (CORDEIRO, 2007, p. 21).

Ainda segundo a autora, a essa função política correspondia a arte do bem falar, argumentar de forma clara e natural, sendo, na maioria das vezes, necessário os professores (neste caso, os sofistas) para corroborarem com essa educação política.

\section{OS ESTUDOS SEMÂNTICOS}

Iniciamos nosso estudo apropriando-nos da pesquisa de Marcuschi (2008), por meio da qual apreciamos o conceito de Linguística enquanto disciplina. Conhecido no meio acadêmico por seu trabalho com a Linguística Textual, o autor também produz textos relacionados à análise dos gêneros textuais. No livro Produção textual, análise de gêneros e compreensão, há um capítulo intitulado Breve excurso sobre a teoria linguística no século XX. E ali compreendemos como surgiu, por meio dos estudos linguísticos, a Semântica enquanto disciplina.

De acordo com Marcuschi (2008), os estudos linguísticos tiveram início há mais de 2500 anos, com Panini, na Índia, e sua motivação deu-se por meio da análise de textos produzidos na esfera da religião e da política; "a idéia da arbitrariedade do signo e de seu caráter representacional vem de Platão e Aristóteles, que levantaram os pilares da semântica e da sintaxe" (p.26).

Durante o século XX, a Linguística passou a ser considerada uma ciência autônoma e, em sua fase inicial, incorpora a teoria de Saussure, afirmando que a língua é uma instituição social, totalmente organizada, que pode ser estudada por si mesma e considerada um sistema autônomo de significação, bem como um sistema de signos arbitrários. 


\section{SEMINÁRIO DE PESQUISA EM CIÊNCIAS HUMANAS - SEPECH \\ Humanidades, Estado e desafios didático-científicos \\ Londrina, 27 a 29 de julho de 2016}

Essa tendência tinha uma longa e frutífera tradição que irá perdurar até os anos 30 do século XX, juntamente com a nova visão estruturalista surgida no primeiro quartel do século XX. Saussure deu origem à chamada lingüística científica, que ficou conhecida a partir de seu Curso de Lingüística Geral desenvolvido entre 1911-1913 e publicado postumamente em 1916 por seus alunos (MARCUSCHI, 2008, p. 27).

A teoria saussuriana vigorou para além da metade do século $\mathrm{XX}$, principalmente na América do Norte, onde, paralelamente, ocorre a perspectiva bloomfieldiana, tida como não tão elaborada filosoficamente. "Pois é de ressaltar a qualidade da reflexão filosófica em Saussure, o que não ocorria em Leonard Bloomfield (1887- 1949), um behavorista despretensioso sob o ponto de vista epistemológico" (MARCUSCHI, 2008, p. 30).

Estruturalistas, formalistas e funcionalistas, cada um em seu tempo, tentavam mostrar qual a importância real da língua. E, inserido nesse quadro, Saussure explana sobre certas dicotomias, a fim de definir o objeto de estudo da linguística. Para isso, teoriza com sua principal dicotomia: 'langue' e 'parole'. Com o passar do tempo, surge Chomsky, com a teoria do inatismo, em que afirmava ser a faculdade mental a responsável pela língua, enfocando o estudo da frase.

Segundo Marcuschi, há outras vertentes que, ao longo do século XX, apresentaram o que foi chamado de funcionalistas; estes, representados por Nicolai Trubetzkoy e Roman Jackobson (Escola de Praga), Louis Hjelmslev (Escola de Copenhague), John Firth (Escola de Londres). Temos, dessa forma, em 1950, a corrente behavorista de Bloomfield e, em 1960, o gerativismo presente em Chomsky. Portanto, os estudos linguísticos são inicialmente pautados em Saussure, Bloomfield e Chomsky. Uma das ramificações da Linguística é a Semântica e, como sabemos, a Semântica, enquanto disciplina, tem um objeto de pesquisa: o estudo da significação das formas linguísticas; mas, definir significação não é atividade das mais fáceis.

De acordo com Pires de Oliveira, "podemos afirmar que a Semântica busca descrever o 'significado' das palavras e das sentenças, mas devemos, então, definir esse conceito" (2006, p. 17). O problema é que não há um consenso entre os pesquisadores da área. O significado pode ser atribuído, por exemplo, conforme a linha teórica utilizada, e a complexidade do estudo está em haver causas de natureza diversa para as mudanças de significação. Dentre estas causas, está o momento em que o texto foi escrito. E o significado descreve situações de fala muito diferentes, sua percepção pode depender de conhecimentos diversificados e do conceito teórico previamente adotado. "Essas perguntas, caras ao semanticista, levam inevitavelmente a enfrentar a questão espinhosa da relação entre linguagem e mundo e, consequentemente, a buscar uma resposta sobre como é possível (se é que é possível) o conhecimento" (PIRES de OLIVEIRA, 2006, p. 18).

A autora afirma que há várias semânticas; dentre estas, a Semântica Formal, a Semântica Cognitiva e a Semântica da Enunciação. Segundo a autora, "a Semântica Formal descreve o problema do significado a partir do postulado de que as sentenças se estruturam logicamente" (PIRES de OLIVEIRA, 2006, p. 19). É a Semântica da lógica e do pensamento estruturalista, pautada em Frege. Por sua vez, a Semântica Cognitiva expressa o significado como uma área central de investigação na linguagem, colocando, ao centro, a sintaxe, por isso, considera que o significado é 


\section{SEMINÁRIO DE PESQUISA EM CIÊNCIAS HUMANAS - SEPECH \\ Humanidades, Estado e desafios didático-científicos \\ Londrina, 27 a 29 de julho de 2016}

motivado dentro da organização sintática. Já à Semântica da Enunciação cabe um modelo informacional em que a linguagem constitui o mundo, e é vista como argumentação, daí ser também denominada de Semântica Argumentativa.

De acordo com a pesquisadora, para o estruturalismo de vertente saussuriana, o significado era definido como uma unidade de diferença. Enquanto isso, para a Semântica Formal, "o significado é um termo complexo que se compõe de duas partes, o sentido e a referência" (PIRES de OLIVEIRA, 2006, p. 18). E para a Semântica da Enunciação, "o significado é o resultado do jogo argumentativo criado na linguagem e por ela". No modelo da Semântica Cognitiva, o significado é somatório e adquirido por meio de nossas relações com o mundo.

Desde Aristóteles, a Semântica Formal mostra as relações de significado por meio do conteúdo e das expressões, são as chamads relações lógicas. Frege (18481925) muito contribuiu para uma definição de significado. Assim, "o estudo científico do significado só é possível se diferenciarmos os seus diversos aspectos para reter apenas aqueles que são objetivos" (PIRES de OLIVEIRA, 2006,p. 20). Nessa perspectiva, o sentido é carregado pela interpretação própria de cada indivíduo, chegando a uma possível referência no mundo. $\mathrm{O}$ sentido nada mais seria que a imagem compartilhada.

Para Frege, um nome próprio é capaz de carregar um sentido e uma referência, pois estes nomes representam um pensamento completo passível de se encontrar uma referência no mundo. Portanto, “ a Semântica Formal considera que há pressuposição quando tanto a verdade quanto a falsidade da sentença dependem da verdade da sentença pressuposta" (PIRES de OLIVEIRA, 2006, p. 26). Ducrot acredita que a Semântica Formal concebe a linguagem como um meio pelo qual alcançamos a verdade e, assim, adquirimos um conhecimento seguro sobre o mundo.

É um lugar comum na linguística atual a afirmação de que a argumentatividade é instrínseca à linguagem humana e de que, portanto, todos os enunciados são argumentativos. Essa posição deve-se aos trabalhos de Oswald Ducrot e Jean Claude Anscombre, que operam com as noções de retórica e de argumentação. Deve-se, no entanto, considerar que esses termos têm, na obra dos dois linguístas franceses, um sentido muito diferente daquele que eles têm na tradição retórica que vem de Aristóteles. Para eles, a argumentação é o estudo das orientações semânticas dos enunciados e dos encadeamentos que as expressam (FIORIN, 2014, p. 54).

Oliveira, em texto publicado no livro Semântica e Estilística: dimensões atuais do significado e do estilo, afirma:

Vale observar que, bem antes de Bloomfield e Chomsky surgirem no cenário acadêmico, a semântica já havia sido instituída por Michel Bréal, no final do século XIX. E ela foi instituída por um viés historicista: ele propusera a semântica como sendo o estudo das mudanças dos significados das palavras (2014, p. 159).

$\mathrm{Na}$ concepção da Semântica Argumentativa, "a linguagem constitui o mundo, por isso não é possível sair fora dela. A Semântica da Enunciação certamente se inscreve nessa perspectiva [...]" (PIRES de OLIVEIRA, 2006, p. 27). A referência, no 


\section{SEMINÁRIO DE PESQUISA EM CIÊNCIAS HUMANAS - SEPECH \\ Humanidades, Estado e desafios didático-científicos \\ Londrina, 27 a 29 de julho de 2016}

entanto, acaba sendo uma ilusão da linguagem, e como estamos inseridos nela, utilizamos o fenômeno da dêixis - os dêiticos - os quais permitem uma sensação de estar fora da língua. Para Ilari e Geraldi (1987), esse fenômeno é composto pelos itens gramaticais, (geralmente, o presente do indicativo, primeira e segunda pessoas do verbo e pronomes demonstrativos) e permite identificar as pessoas e coisas por meio da situação de fala. "Os dêticos realizam o fenômeno da dêixis (ato de mostrar), que é um dos traços que distinguem a linguagem humana das linguagens artificiais, tornando-a apropriada para o uso em situações correntes" (ILARI e GERALDI, 1987, p. 66).

A linguagem é um jogo de argumentação, cujo objetivo é construir um mundo e, a partir dele, convencer nosso interlocutor da verdade criada por nós. "Afinal, a razão de ser da linguagem é a interação social, que se lastreia na produção de sentidos, lastro esse que dá sustentação à estruturação sintática dos elementos lexiciais" (OLIVEIRA, 2014, p. 159).

Para o autor, além da Teoria dos Atos de Fala, com base na Pragmática, outras áreas consolidam-se, como é o caso da Sociolinguística Interacional, Análise da Conversação, Linguística Textual, Análise do Discurso de linha francesa. "Em todas essas áreas, o conceito de significado desempenha um papel importante já que a produção de sentidos dá lastro à interação, à produção textual falada e escrita" (OLIVEIRA, 2014, p. 162).

Sobre a Teoria dos Atos de Fala, Ilari e Geraldi (1987) afirmam que ela é usada para relatar verbalmente uma ação e realizá-la. Nesse caso, os atos de fala servem para informar reciprocamente, sendo, então, inadequado declarar o início e o fim de uma situação. Segundo eles, "há sempre um quê de frase-feita nas expressões que utilizamos para realizar ações verbalmente; mas a investigação desses aspectos, no que toca ao português, não passou até hoje de um nível exemplificativo e incipiente" (ILARI e GERALDI, 1987, p. 72).

Koch (2003) vê a linguagem como forma de ação e esclarece que a Teoria dos Atos de Fala surgiu com a Filosofia da Linguagem de Austin.

$\mathrm{O}$ ato de fala é direto quando realizado através de formas lingüísticas especializadas para tal fim: certos tempos ou modos verbais, dadas expressões esteriotipadas, determinados tipos de entonação, etc. $\mathrm{O}$ ato de fala indireto (ou derivado) é aquele realizado através do recurso a formas típicas de outro tipo de ato" (KOCH, 2003, p. 20).

Quando interagimos por meio da linguagem, queremos que nossos enunciados tenham força argumentativa suficiente para que nossos fins sejam atingidos. Assim, "[...] só há línguas porque há falantes e só há falantes porque há línguas" (GUIMARÃES, 2002, p. 18). Dessa forma, além dos Atos de Fala e da Dêixis, a Semântica Argumentativa dedica-se ao estudo dos Operadores Argumentativos, para "designar certos elementos da gramática de uma língua que têm a função de indicar ('mostrar') a força argumentativa dos enunciados, a direção (sentido) para o qual apontam" (KOCH, 2003, p. 30). Servem, portanto, para conduzir a uma mesma conclusão. Dentre eles, há operadores que: assinalam o argumento mais forte; somam argumentos a favor de uma mesma conclusão; introduzem uma conclusão relativa a argumentos apresentados em enunciados anteriores; introduzem argumentos alternativos; estabelecem relações de comparação entre elementos; introduzem uma 


\section{SEMINÁRIO DE PESQUISA EM CIÊNCIAS HUMANAS - SEPECH \\ Humanidades, Estado e desafios didático-científicos \\ Londrina, 27 a 29 de julho de 2016}

justificativa ou explicação; contrapõem argumentos; têm por função introduzir no enunciado conteúdos pressupostos e aqueles que se distribuem em escalas opostas.

Por fim, dentre os ramos dos estudos semânticos, há a Semântica Cognitiva, cujo modelo de significado é aquele que é central na linguagem, não sendo mais a sintaxe o centro das pesquisas, como queriam os gerativistas. "A forma deriva da significação, porque é a partir da construção de significados que aprendemos, inclusive a lógica e a linguagem, daí a Semântica Cognitiva se inscrever no quadro do funcionalismo" (PIRES de OLIVEIRA, 2006, p. 34). As pesquisas, nesta linha, pretendem combater o pressuposto "de que a linguagem está numa relação de correnspondência direta com o mundo", considerando que o significado é motivado de dentro para fora, mentalmente.

Ora, se a argumentação é tomada de posição contra outra posição, a natureza dialógica do discurso implica que os dois pontos de vista não precisam ser explicitamente formulados. $\mathrm{Na}$ medida em que um discurso é sempre um discurso sobre outro discurso, todos os discursos são argumentativos, pois todos eles fazem parte de uma controvérsia, refutando, apoiando, contestando, sustentando, contradizendo um dado posicionamento. Todos os discursos são argumentativos, pois são uma reação responsiva a outro discurso (FIORIN, 2014, p. 69).

\section{MANCHETE: JUSTIÇA CONSIDERA GREVE ABUSIVA E PEDE RETORNO IMEDIATO DOS PROFESSORES}

O texto a ser analisado neste tópico reservado à Folha de Londrina leva o título "Justiça considera greve abusiva e pede retorno imediato dos professores" e foi escrito pela equipe de redação do Bonde, no dia 04/03/2015, às $18 \mathrm{~h} 30$. Neste texto, destacamos enunciados proferidos por Luiz Mateus de Lima, desembargador do Tribunal de Justiça do Paraná (TJ-PR); “o desembargador justifica que é 'inegável' o prejuízo sofrido pelos estudantes sem aulas mesmo que "haja a reposição de tal carga horária no futuro" ( $p$. online). Sobre o termo inegável, o Dicionário da Língua Portuguesa (Editora Porto, 2015) descreve como "que não se pode negar; evidente; incontestável". E é exatamente isso, nossos alunos perderam um equivalente a um mês de aulas, que, somadas às circunstâncias precárias de nossas escolas, afetam o rendimento anual. Sem contar que, por meio deste trabalho, analisamos somente algumas publicações relativas à primeira fase da greve; a História registra que continuou, após breve retomada das aulas, houve um segundo e maior tempo de paralisação e ainda neste ano letivo corre-se o risco de nova greve. E, como salienta o desembargador, embora a carga horária possa ser reposta o prejuízo aos estudantes é um fato. Some-se a este fato, o prejuízo causado na identidade dos educadores e no apreço da sociedade por seus políticos.

Vejamos o fragmento textual: "Por derradeiro, ainda que o interesse da categoria sindical envolvida seja legítimo e pautado na legalidade, deve prevalecer o direito essencial/fundamental à educação, acrescenta" ( $\mathrm{p}$. online). A que tipo de educação refere-se? De qual qualidade? Os estudantes têm o direito a uma educação de boa qualidade, estão sendo privados disso, quando seus professores sentem-se desrespeitados e desmotivados. E, naquele um mês de paralisação talvez aprendeu-se mais nas ruas do que em salas de aula regidas por profissionais feridos em sua dignidade. 


\section{SEMINÁRIO DE PESQUISA EM CIÊNCIAS HUMANAS - SEPECH \\ Humanidades, Estado e desafios didático-científicos \\ Londrina, 27 a 29 de julho de 2016}

O texto em análise aproxima os lexemas "legalidade" e "legitimidade", o que favorece ao leitor a reflexão sobre essas distinções, pois nem tudo o que é legal é legítimo, como exemplo disso, temos a apropriação de recursos de um fundo previdenciário por outro.

O desembargador aponta milhares de estudantes como as maiores vítimas. No caso da greve na área da educação, muitas foram as vítimas. E, uma das acepções do lexema vítima é a de "pessoa sacrificada aos interesses ou paixões alheias". Esta lexia está ligada ao sentido de dano, violência, infortúnio, desgraça, catástrofe, revolta; juridicamente, refere-se ao sujeito passivo do ilícito penal. No entanto, o termo 'vítimas' aparece no plural, referindo-se a milhares de alunos, os funcionários não são vistos pelo juiz como vítimas da administração pública, tanto que a greve é considerada 'abusiva', houve a previsão de multa diária no caso da volta às aulas não ocorrer no prazo estipulado de vinte e quatro horas, ou seja, no dia seguinte à decisão judicial. Apesar disso, não se atesta o interesse dessa categoria sindical como ilegítimo ou ilegal, exige-se o retorno imediato dos professores mesmo se seus interesses forem legítimos e pautados na legalidade, pois busca-se preservar um bem maior: o direito à educação. Diante do apoio da população ao movimento grevista e criticando a falta de diálogo com os trabalhadores, o sindicato da categoria recorreu da decisão.

Bakhtin afirma que todos os nossos enunciados nascem de enunciados já-ditos e buscam a reação-resposta do outro, aquele a quem nós o endereçamos. Por isso, os enunciados se relacionam uns com os outros, não existindo enunciado isolado. Dessa forma, o acabamento do enunciado é apenas um acabamento que possibilita a emergência de outro enunciado (SILVEIRA et al, 2012, p. 32).

\section{CONCLUSÃO}

O processo de leitura de textos jornalísticos tem mudado com o passar do tempo. Há algum tempo as pessoas mais letradas esperavam amanhecer o dia para comprar o jornal, ou buscá-lo na porta de casa. Hoje, também podem acessá-lo no celular, tablet, computador. Essa facilidade permitiu a interação leitor-jornal devido as publicações em tempo real. Yoshikawa e Gonçalves observam que

Assim, o jornalismo digital tem características diferentes dos outros veículos de mídia impressa. No jornal impresso, o leitor recebe a informação, tende a aceitar o que lhe é oferecido, comporta-se com maior passividade, sempre dependendo do seu grau de letramento. Por sua vez, na Internet, o usuário da rede tende a apresentar um perfil mais pró-ativo, acessa variadas fontes durante o processo de seleção do conteúdo que atendem melhor aos seus interesses. Diante da tela do computador, diariamente, aparece uma quantidade abundante de informações e o internauta não se sente obrigado a estabelecer um contrato fiduciário a qualquer veículo digital. Em contrapartida, com relação aos jornais impressos, ocorre o oposto. O leitor não costuma comprar ou assinar o jornal por impulso. Ciente dessa situação, a linha editorial do jornal busca estar de acordo com o perfil socioeconômico do seu público-alvo (2012, p. 79). 


\section{SEMINÁRIO DE PESQUISA EM CIÊNCIAS HUMANAS - SEPECH \\ Humanidades, Estado e desafios didático-científicos \\ Londrina, 27 a 29 de julho de 2016}

Dessa forma, é para esse perfil de "leitor dos meios digitais" que os textos analisados foram publicados. Precisávamos saber, imediatamente, o que acontecia, quais eram os mandos e/ou desmandos do governador, qual a procedência da greve. Com isso, podíamos elencar os enunciados proferidos, buscar outras fontes, conhecer, detalhadamente, cada instância. E é assim que fizemos para elegermos os textos exemplificativos de nossa argumentação teórica.

Portanto, mesmo com a breve explanação sobre a Semântica Argumentativa e sobre os conceitos de funcionalismo público, tentamos mostrar que a mídia costuma alegar que procura ser imparcial, mas a escolha lexical a que se submete deixa claro a que veio. Percebemos que os jornais Folha de Londrina (Portal Bonde) e Jornal de Londrina mostraram-se favoráveis aos anseios das categorias em greve, mas, mesmo assim, buscam amparo em fontes oficiais. Afinal, "[...] a argumentação não está pressuposta nas palavras e enunciados da língua nem depende somente de fatores internos a ela" (SANTOS, 2012, p. 141). Como vemos, as fontes elencadas para dizer sobre a greve dos profissionais da educação nem sempre foram os professores, fato que pode estar associado à visão da identidade das pessoas pertencentes a este grupo profissional e, até mesmo, ter reflexos sobre essa imagem social.

\section{REFERÊNCIAS}

BONDE. Justiça considera greve abusiva e pede retorno imediato dos professores. Portal Bonde. Londrina, 04 de mar. de 2015. Educação. Disponível em: < http://www.bonde.com.br/?id_bonde=1-12--36-20150304>. Acesso: 07 abr. 2015.

CORDEIRO, Isabel Cristina. Argumentação e leitura: uma relação de complementaridade. Tese (Doutorado em Estudos da Linguagem) - Universidade Estadual de Londrina, Centro de Letras e Ciências Humanas, Programa de PósGraduação em Estudos da Linguagem. Londrina, 2007.

GUIMARÃES, Eduardo. Semântica do Acontecimento. Campinas: Pontes, 2002.

ILARI, Rodolfo; GERALDI, João Wanderley. Semântica. 3 ed. São Paulo: Editora Ática, 1987.

KOCH, Ingedore G. Villaça. A inter-relação pela linguagem. São Paulo: Contexto, 2003.

MARCUSCHI, Luiz Antônio. Produção textual, análise de gêneros e compreensão. São Paulo: Parábola Editoria, 2008. (Educação Linguística, 2).

OLIVEIRA, Luciano Amaral. Semântica e formação do leitor crítico. In: OLIVEIRA, Esther Gomes de; SILVA, Suzete (orgs). Semântica e estilística: dimensões atuais do significado e do estilo (Homenagem a Nilce Sant'Anna Martins). Campinas, SP: Pontes Editores, 2014. p. 157-175. 


\section{SEMINÁRIO DE PESQUISA EM CIÊNCIAS HUMANAS - SEPECH \\ Humanidades, Estado e desafios didático-científicos \\ Londrina, 27 a 29 de julho de 2016}

PIRES de OLIVEIRA, Roberta. Semântica. In: MUSSALIM, Fernanda; BENTES, Ana Christina (orgs). Introdução à lingüística: domínios e fronteiras. v.2, 5 ed. São Paulo: Cortez, 2006. p. 17-46.

SILVEIRA, Ana Paula Kuczmynda da; ROHLING, Nívea; RODRIGUES, Rosângela Hammes. A análise dialógica dos gêneros do discurso e os estudos do letramento: glossário para leitores iniciantes. Florianópolis: DIOESC, 2012.

YOSHIKAWA, Luisa Miyuki; GONÇAVES, Lidia Maria. O hipertexto nos jornais Folha de Londrina e International Press sobre o grande terremoto ocorrido no leste do Japão. In: BOLETIM. Centro de Letras e Ciências Humanas. UEL Londrina - $\mathrm{n}^{\circ} 62-$ p. $77-96-$ jan/jun. 2012.

SANTOS, Givan José Ferreira dos. A argumentação vista sob diferentes abordagens de estudo da linguagem. In: BOLETIM. Centro de Letras e Ciências Humanas. UEL Londrina $-\mathrm{n}^{\circ} 62-$ p. 139-156 - jan/jun. 2012.

\section{ANEXOS}

Justiça considera greve abusiva e pede retorno imediato dos professores

Redação Bonde - 04/03/2015 -- 18:30

O Tribunal de Justiça do Paraná (TJ-PR) determinou na tarde desta quarta-feira (4) o retorno imediato dos professores às salas de aula após 24 dias de greve. $\mathrm{Na}$ manhã desta quarta, os professores haviam decidido manter a paralisação por tempo indeterminado em assembleia realizada no estádio Durival de Brito, a Vila Capanema, em Curitiba.

Na decisão, o desembargador Luiz Mateus de Lima prevê multa diária de R\$ 20 mil em caso de descumprimento e estipula prazo de 24 horas para que os filiados da APP Sindicato sejam comunicados da voltas às aulas. O desembargador justifica que é "inegável" o prejuízo sofrido pelos estudantes sem aulas mesmo que "haja a reposição de tal carga horária no futuro". Os grevistas também estão proibidos de obstruir, de qualquer modo, o acesso a escolas ou a qualquer outro órgão público estadual ou de impedir o trabalho de outros servidores públicos. "A greve é extremamente prejudicial a milhares de estudantes, os quais estão sendo as maiores vítimas", afirma o desembargador na decisão. Lima ainda considera a greve abusiva, pois compromete o "interesse da coletividade". "Não me parece justo e legal comprometer toda a sociedade, maior afetada nesse momento, pelo movimento paredista", afirma. "Por derradeiro, ainda que o interesse da categoria sindical envolvida seja legítimo e pautado na legalidade, deve prevalecer o direito essencial/fundamental à educação", acrescenta.

APP vai recorrer

Em nota a a APP-Sindicato informou que não foi notificada da decisão, sendo comunicado por meio da imprensa. A entidade afirmou que os professores vão continuar em greve. "A interpretação da direção é de que a greve vem seguindo todos os procedimentos previstos na lei", argumenta a APP que promete recorrer da decisão. 


\section{SEMINÁRIO DE PESQUISA EM CIÊNCIAS HUMANAS - SEPECH \\ Humanidades, Estado e desafios didático-científicos}

Londrina, 27 a 29 de julho de 2016

O sindicato ainda criticou a posição do governo que entrou com o pedido do retorno às aulas na Justiça. "Lamentamos a decisão de um governo que se nega ao diálogo com os trabalhadores e recorre a outros poderes para tentar por fim a uma manifestação legítima da categoria que conta com o apoio incondicional da população", disparou. 